J. Lake Sci. (湖泊科学), $2006, \mathbf{1 8}(4): 414-418$

http:// www. jlakes. org. E-mail: jlakes@ niglas. ac.cn

(c) 2006 by Journal of Lake Sciences

\title{
关于太湖流域防洪标准的讨论*
}

\author{
徐向阳 ${ }^{1}$, 张 超 ${ }^{2}$, 沈晓娟 ${ }^{2}$
}

(1: 河海大学水文水资源与水利工程科学国家重点实验室,南京 210098)

$(2$ : 河海大学水资源环境学院,南京 210098$)$

\begin{abstract}
摘 要: 在分析流域、区域、城市防洪工程作用的基础上, 提出以 11 项骨干工程为核心组成太湖流域防洪体系, 其主要作 用是在设计条件下保证流域整体防洪安全,并建议按流流域 GDP 的 $0.2 \%-0.3 \%$ 洪灾损失作为判断和控制流域性洪灾 的经济指标. 根据太湖流域防洪标准的基本涵义,讨论了设计暴雨时空分布与流域防洪体系规划建设的关系. 最后, 在分 析太湖流域现状防洪标准的基础上,从防洪减灾角度,提出提高流域防洪能力的建议.
\end{abstract}

关键词: 防洪标准; 防洪体系;设计暴雨;太湖流域

\section{Discussion of Taihu Basin flood control standards}

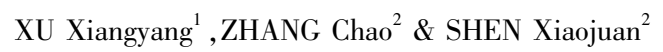

(1: State Key Laboratory of Hydrology-Water Resources and Hydraulic Engineering, Hohai University, Nanjing 210098 ,P. R. China)

(2: College of Water Resources and Environment, Hohai University, Nanjing 210098,P. R. China)

\begin{abstract}
Abstrsct: According to the analysis on basin , regional and urban flood control projects in Taihu basin, the basin flood control system mainly consist of 11 key engineerings and its function is to ensure safety of Taihu basin under the design flood conditions. The critical value of flood loss to equal $0.2 \%-0.3 \%$ GDP of the basin is regard as a index judging and controlling basin flood disaster. Based the meaning of flood control standards for Taihu basin, relationship between space-time distributing of design storm and planning of the flood control system are analysed. Lastly, the practical flood control standards of the basin is discuss and some suggestions are put forwarded to increase basin flood control capacity.
\end{abstract}

Keyword : Flood control standards; flood control system; design storm; Taihu Basin

防洪标准是进行流域防洪规划和确定防洪工程规模的最重要指标,根据水文计算和水文统计的基本 概念和方法 ${ }^{[1,2]}$, 太湖流域防洪标准可以定义为:在太湖流域规划或设计条件下, 由于流域防洪体系受到洪 水破坏, 致使全流域遭受洪涝灾害的概率, 用致灾洪水的频率或重现期来表达. 在以往对太湖流域防洪的讨 论中, 大部分文献侧重讨论的是如何根据流域防洪标准, 规划实施各类工程和非工程措施, 提高流域防洪能 力. 1991 年和 1999 年太湖流域特大洪涝灾害发生后, 人们认识到太湖成灾暴雨历时对流域防洪规划的影 响 ${ }^{[3,4]}$,开始分析设计暴雨历时与防洪标准的联系,但主要还是探讨如何调整规划方案以达到的流域防洪 标准 ${ }^{[5,6]}$. 由于防洪标准定义看起来很明确, 极少有人以流域防洪标准为专题进行系统深人的论述和讨论. 但是, 在太湖流域防洪规划中涉及流域防洪标准时,却存在一些问题值得商榷和讨论. 首先, 太湖流域水系复 杂,水利工程众多,防洪标准中涉及的流域防洪体系的内涵是什么; 其次,太湖流域是经济高度发达的地区,必 须作出流域性洪灾的定义, 才能确定流域防洪体系的保护目标和要求; 第三, 太湖流域水情非常复杂, 人类活 动对水文特性影响显著,如何选择代表性水文变量并推求符合防洪标准的设计水文过程. 正确地认识这些问 题,才能合理制定和应用流域防洪标准,为太湖流域防洪规划设计与管理工作提供科学的决策依据. 


\section{1 太湖防洪体系的组成与作用}

解放以来, 太湖流域进行了大量的水利工程建设, 极大地提高了抗洪排涝的能力. 目前, 太浦河、望虞 河、环湖大堤等 11 项治太骨干工程已基本完成, 太湖流域初步形成洪水北排长江、东出黄浦江、南排杭州 湾, 充分利用太湖调蓄, “蓄泄兼筹、以泄为主” 的流域防洪骨干工程布局 ${ }^{[7]}$, 成为流域防洪工程的主体. 流 域内 $51 \%$ 的平原地区修建了圩区,包围面积 $14500 \mathrm{~km}^{2}$, 圩区排涝能力达 $10000 \mathrm{~m}^{3} / \mathrm{s}^{[8]}$; 区域性河道治理、堤 防建设,沿江和沿海排涝工程建设也得到加强. 为了改变城市防洪标准偏低的状况, 上海市、各地级市和部 分县市在原有城市防洪工程基础上,已经制定了城市防洪规划.

虽然流域、区域和城市防洪工程在太湖流域防洪中均的发挥着重要作用,但各类工程的规模、保护对 象、保护范围、防洪标准存在明显差别. 城市防洪工程尺度较小, 一般仅承担中心城区的防洪任务,防洪规划 多为抵御 100-200 年重现期的洪水,远高于流域防洪标准. 区域防洪工程规模有限, 只能抵御局地暴雨洪 涝灾害. 因此, 当太湖流域遭遇洪水时,城市防洪工程和区域防洪工程作用一般是尽可能是保护城市或局部 地区的安全, 并不以流域整体防洪安全为主要目标, 有时甚至加剧流域洪涝情势. 例如, 圩区建设控制了许 多排水河道, 降低河道泄水能力, 又减少了洪水调蓄面积; 同时, 由于排涝能力的增强, 在遭遇大洪水时期, 圩区会泵站开足马力向外河网排水,造成流域河网水位的抬高.

因此,在研究太湖流域的防洪标准时, 流域防洪体系中的防洪工程应该是指受流域控制调度的防洪工 程. 根据水利部《关于加强太湖流域 $2001-2010$ 年防洪建设的若干意见》,在今后一段时间内, 流域防洪体 系中的主体防洪工程是 11 项治太骨干工程以及受流域调度的重要防洪水库. 流域防洪体系还必须包含流 域非工程防洪措施的配合,包括流域洪水预报、防洪调度、防洪抢险措施等. 在流域防洪设计条件下,流域防 洪体系必须正常运行,保证流域整体安全.

\section{2 流域防洪要求}

\section{1 社会经济及洪涝灾害}

太湖流域是我国经济最发达的地区之一. 至 2003 年底,太湖流域流域人口 3700 万; 当年国内生产总值 1.51 万亿元, 约占全国的 $13 \%$, 人均约 4900 美元, 为全国平均值的 4.5 倍; 财政收人 4123 亿元, 占全国的 $19 \%$ 。随着经济社会的发展,太湖流域的城镇建设迅速,城市化率达 $60 \%$, 已形成一个由特大、大、中、小城 市、建制镇等级齐全的城镇体系,包括 500 万人口以上特大城市 1 座, $100-500$ 万人口的大城市 1 座, $50-$ 100 万人口城市 3 座, $20-50$ 万人口城市 9 座.

太湖流域绝大部分城市、村镇和农田位于太湖平原河网地区,极易遭受洪涝灾害的侵袭. 建国以来,已 经遭受多次重大洪涝灾害,造成很大的经济损失. 20 世纪太湖流域发生的大洪水年份为 1911、1921、1931、 $1949 、 1954 、 1957 、 1962 、 1963 、 1969 、 1983 、 1991 、 1995 、 1999$ 年等. 其中, 解放后发生的特大洪水有三次, 分别是 1954 年、1991 年和 1999 年洪水. 1954 年流域洪水,最大 90 天降水量频率达 50 年一遇,受灾面积 12000 $\mathrm{km}^{2}$, 除上海市和杭州市外, 大部分城市被淹, 太湖高水位持续达 $50 \mathrm{~d}$ 之久; 1991 年流域洪水,30d 降雨量 $490 \mathrm{~mm}$, 降雨集中, 强度大, 造成严重水灾, 直接经济损失 114 亿元;1999 年流域洪水, 暴雨中心分布广, 降雨 集中, 总量大, $30 \mathrm{~d}$ 降雨超过百年一遇, 流域大部分地区受到洪水灾害, 直接经济损失达 141 亿元 $^{[8]}$.

\section{2 防洪保护要求}

太湖流域防洪体系主要针对大范围、长历时暴雨洪水,将太湖流域整体作为保护的对象,最大限度降低 流域洪涝灾害损失. 在流域规划建设中, 常需考虑重点防护区域和重点保护对象. 通过对太湖流域社会经 济、地形地貌、历史洪涝灾情分析, 重点防护地区是太湖周边的武澄锡虞区、阳澄淀泖区、杭嘉湖区; 重点保 护对象为流域内的重要城市,包括上海市, 苏州、无锡、常州、镇江、杭州、嘉兴、湖州等八座城市.

在流域防洪设计条件下,太湖流域防洪体系按照规定的预报调度方案运行,尽快排除流域涝水,按规划 要求控制各水利分区、重点保护对象的最高洪水位及洪水历时. 由于城市防洪标准一般高于流域防洪标准, 当各城市按规划防洪工程正常运行时,流域防洪体系可以确保城市的防洪安全. 在区域防洪工程正常运行 条件下,各水利分片的的圩区、乡镇、农田基本不受灾. 
太湖流域面积为 $36895 \mathrm{~km}^{2}$, 主要分属江苏省、浙江省、上海市. 流域防洪体系必须兼顾全流域防洪需 求,流域防洪规划依据的设计洪水往往是基于均匀分布的原则. 但实际发生的暴雨洪水多数在空间分布是 不均匀的,历时灾情资料显示, 流域性洪涝灾害往往是以 1-3 个水利分区的特大暴雨洪涝所形成. 例如, 1991 年太湖流域雨量约为 30-40 年一遇, 而湖西区和武澄锡虞区雨量为 $100-200$ 年一遇, 远高于流域雨 量,造成湖西区和武澄锡虞区的特大洪灾; 1999 年的洪涝灾害则主要发生在杭嘉湖和上海地区. 因此, 规划 建设的太湖流域防洪体系, 虽然不可能保障特大暴雨发生条件下, 暴雨中心水利分区完全不受洪涝损失, 但 应该大幅度降低暴雨中心区洪涝灾害的程度, 从而使得流域总的经济损失低于规定的控制标准. 根据太湖 流域以往洪涝灾情统计分析和评估 ${ }^{[9]}$, 随着流域防洪能力提升和国民经济发展, 洪涝灾害损失率显著降 低. 1999 年流域 30-45 日暴雨重现期为 100-150 年, 远超过了流域防洪标准, 但洪涝损失仅占流域 GDP 的 $1.6 \%$, 远低于 1991 年的 $6.7 \%$. 美国在 20 世纪 30 年代, 洪水损失占 GDP 的 $0.334 \%$, 其中发生特大洪 水的 1937 年超过了 $1 \%$; 而到 20 世纪 90 年代, 美国年平均洪水损失占 GDP 的 $0.068 \%$, 其中密西西比河流 域 1993 年发生了超过 200 年一遇的洪水,年洪水损失所占 GDP 的比例仅为 $0.25 \%$. 与之相比, 20 世纪 90 年代中国各年洪水损失占 GDP 的比值为 $1.13 \%-3.84 \%{ }^{[10]}$. 作为我国经济最发达的太湖流域,应该提出 较高的防洪控制要求. 建议在遭遇流域防洪标准的洪水条件下, 以洪涝直接经济损失不超过流域内国内生 产总值 $0.2 \%-0.3 \%$ 为防洪规划控制标准,并以是否超过这一损失作为判断流域性洪涝灾害的标准. 考虑 到洪灾损失率随 GDP 的增加而减少,近期控制标准可取损失率上限,远期取下限. 鉴于这一控制标准取值 的敏感性,其合理性和可行性还需经过流域管理机构组织有关专家进行论证.

\section{3 流域防洪标准的讨论}

\section{1 代表性水文变量选择}

太湖流域主要经济区位于太湖平原区,地面高程大部为 1.0-3.0m(黄海基面),约 50\% 以上面积的地 面高程在汛期洪水位以下. 平原地区河道水面比降平缓, 河网尾问受潮水顶托, 泄水不畅, 每逢暴雨, 河湖水 位暴涨, 高水位持续时间长, 易酿成洪涝灾害 ${ }^{[6]}$. 因此, 与太湖流域洪涝灾情最为密切的是平原区的洪水 位. 由于太湖是流域的最大调蓄湖区, 汛期可以承接上游山区及湖面暴雨径流,通过调蓄后经下游平原河网 排出流域,对调控太湖流域整体水位至关重要. 故太湖水位基本代表了流域洪水位高低状况. 例如, 1954 年 特大洪灾,太湖最高水位 $4.65 \mathrm{~m}$; 1991 年特大洪灾,太湖水位达到超历史的 $4.79 \mathrm{~m}, ; 1999$ 年特大洪灾, 太湖 水位又创历史新高 $5.08 \mathrm{~m}$. 解放后的最大三次流域性洪涝灾害, 太湖水位也位于历年最高水位的前三甲.

太湖流域洪水位变动受多种因素影响,流域的暴雨过程是最主要的天然影响因素,具有较强的随机性. 但是, 人类活动对洪水位的影响也是非常显著的. 随着城市化进程及水利工程建设,流域产流和汇流特性发 生了明显的变化, 尤其是人们通过水利工程调度,控制着湖泊、河道、圩区的流量及水位过程. 因此,太湖流 域的水位已不是一个完全的随机变量,无法用水位频率来代表流域防洪标准.

与水位相比,太湖流域的暴雨特性基本不受人类活动的影响,在流域规划的土地利用、水利工程及调度 方式、边界水文条件下, 暴雨特性与流域洪水位的关系是很密切的, 由流域设计暴雨可以推求出相应的设计 洪水位. 因此, 按照水文统计原理和水文计算规范的原则, 在太湖流域采用暴雨频率来表达流域防洪标准是 比较合适的.

\section{2 设计暴雨与防洪标准关系分析}

由于太湖流域特殊的气候条件和地理位置, 洪水主要由长历时、大范围的梅雨以及高强度、短历时的台 风雨造成. 由于太湖流域调蓄能力强、排泄能力弱, 长历时、高强度的梅雨是造成全流域洪涝灾害的主要成 因. 近年来, 随着治太 11 大骨干工程竣工, 区域防洪工程和城市防洪工程的建设, 流域抵御洪涝灾害的能力 得到加强. 与此同时, 流域洪水对暴雨过程的响应时间也发生了变化. 根据太湖流域管理局分析,20世纪 90 年代以来, 太湖频频出现超警戒水位, 流域成灾暴雨的雨日天数由 20 世纪 50 年代的 $60-90 \mathrm{~d}$, 缩短到 $30-$ $45 \mathrm{~d}^{[11,12]}$. 太湖的洪水位呈现上涨快, 持续时间长, 退水过程慢的特点 ${ }^{[13]}$.

由于防洪标准是以时段设计雨量的频率来表征的,确定太湖流域洪水位对致灾暴雨的敏感降雨时段是 重要的. 虽然目前太湖流域管理局等部门的研究认为对太湖流域成灾暴雨历时在 20 世纪 90 年代有减少的 
趋势, 但并不能定量确定成灾暴雨的敏感历时. 事实上, 成灾暴雨历时与暴雨量级、时空间分布、水利工程条 件、调度模式等众多因素有关. 暴雨时空分布与设计暴雨计算选用的典型暴雨有关. 在流域防洪规划中,水 利工程条件、调度模式往往也是处于不断的变化和调整之中. 根据这一状况, 在太湖流域防洪规划水文计算 中, 可以采用对典型暴雨同频率缩放方法推求设计暴雨过程,设计时段应该涵盖所有可能的致灾降雨历时. 根据太湖流域设计暴雨和产汇流计算的经验, 建议设计暴雨统计时段可以取 7、15、30、60、90d, 流域前期影 响雨量的统计时段取 $30 \mathrm{~d}$.

对太湖流域历史暴雨资料分析表明,1931 年型和 1954 年型暴雨中心位于上游山丘区,1957 年型暴雨 在流域面上分布比较均匀,1991 年型暴雨中心在流域北部, 1999 年型暴雨中心在流域南部. 由此可见,太湖 流域特大暴雨中心可以出现在流域各处. 按不同的暴雨空间分布方案,推求出的流域洪水空间特性也是不 同的,流域遭受的经济损失也是有差异的,进而影响流域防洪工程的规划. 因此,在选用暴雨空间分布方案 时,可以考虑按有利于流域防洪工程地区均衡布设原则、对流域防洪不利的原则、对流域防洪效益最高的原 则进行综合分析论证. 具体操作时,建议按均匀分布型设计暴雨进行流域防洪规划计算,再采用其他分布类 型暴雨进行校核,满足各种分布的暴雨的设计条件下,规划工程实施后的流域洪涝损失不超过控制标准 (如太湖流域 GDP 的 $0.2 \%-0.3 \%$ ).

\section{3 流域现状防洪能力及问题分析}

1987 年国家计委批复了《太湖流域综合治理总体规划方案》,流域防洪以 1954 年实际降雨过程为设计 典型, 其全流域最大 90 天降雨量约相当于 50 年一遇. 1991 年太湖大水以后,国家决定按总体规范方案全面 开展治太工程建设,至 2004 年已基本完成.

按照 1954 年实际雨型作为设计暴雨, 规划得出的流域防洪体系, 流域防洪标准能够达到 50 年一遇吗? 很多研究均提出疑问 ${ }^{[6,8,12]}$. 事实上,太湖流域自 1991 年洪涝灾情已经揭示, 按太湖流域现状防洪体系, 太 湖流域成灾暴雨历时已经降低至 $30-45 \mathrm{~d}$. 而 1954 年流域 30 天雨量为 $352 \mathrm{~mm}$,仅为 7 年一遇; 45 天雨量为 $489 \mathrm{~mm}$, 为 10 年一遇; 60 天雨量为 $628 \mathrm{~mm}$, 为 20 年一遇. 显然, 按流域雨洪响应时间为 $30-45 \mathrm{~d}$, 若仍以 1954 年实际雨量为设计暴雨,规划出的流域防洪体系的防洪标准低于 20 年一遇. 为此, 1999 年洪水后,水 利部在 2001 年 10 月 26 日的《关于加强太湖流域 $2001-2010$ 年防洪建设的人干意见》中, 要求进一步增建 和完善太湖流域防洪工程, 到 2010 年能够防御不同降雨典型 50 年一遇洪水. 太湖流域管理局根据最新雨 洪资料,对流域防洪规划方案进行了修订和调整 ${ }^{[8,13]}$. 在治太 11 大骨干工程完成后, 太湖流域防洪能力有 了显著提高,但是目前尚未达到 50 年一遇的流域防洪标准,与太湖流域社会经济对流域防洪的要求还有差 距, 而进一步大幅度提高流域防洪标准遭遇瓶颈, 其中最为关键的要点是: (1) 太湖大堤工程基本定型, 说 明在设计条件下,太湖用于调蓄流域洪水库容基本达到上限; (2) 太湖流域的主要排水通道望虞河和太浦 河规模也已经确定, 新辟流域性排水通道存在较大的阻力和困难; ( 3 ) 流域城市化进程及环境用水需求使 得流域河网水系汛期水位有增加的趋势, 降低了流域的抗洪能力.

\section{4 提高流域防洪能力的讨论}

为了保证太湖流域在 2010 年前达到 50 年一遇,将来提高到 100 年一遇的流域防洪标准,使得流域性 洪涝灾害损失不超过控制指标, 必须针对太湖流域防洪问题,制定相应的对策和措施, 提高太湖流域防洪能 力和减小洪灾损失.

重点加强城市的防洪减灾能力: 太湖流域城市是 GDP 的集中生产区, 虽然地级城市防洪规划已经完 成,城市防洪标准规划提高到 $100-200$ 年重现期,但近期很难达到规划标准. 另外,由于流域防洪标准远低 于城市防洪标准, 如果流域性防洪工程发生损坏和事故,势必对下游城市构成重大威胁. 为了最大限度减小 流域洪涝灾害损失,保护城市是流域近期和未来防洪的一个核心任务. 因此, 流域防洪规划中必须考虑到对 城市防洪很敏感的短历时 $(1-7 \mathrm{~d})$ 设计暴雨条件下流域防洪调度对策; 同时,也须考虑对流域影响较大的 较长历时 $(15-90 \mathrm{~d})$ 情况下有利于城市防洪的工程布局, 以及洪水重现期超过流域防洪标准情况下如何保 护下游城市安全的防洪对策.

区域与流域防洪规划相协调:在区域规划和圩区规划中,保持和恢复区域的水面率,尽量少设控制工程 以保证骨干河网的通畅性. 鼓励各省市加强流域沿江、沿海水利片向江、海外排的能力,降低区域汛期洪水 
位,减缓流域防洪体系的压力.

充分发挥非工程措施的防洪作用:通过水情预报和防洪调度, 充分发挥全流域水系和防洪工程的整体 调蓄与外排能力, 以增加流域调节库容和排水总量; 建立健全流域灾情应急系统, 及时进行防洪抢险, 降低 洪涝频次和损失程度; 尽快编制流域洪涝风险图,通过对特大洪水淹没范围和经济损失后果分析,作为制定 各地区防洪标准和编制防洪规划的重要依据, 并从流域损失最小视角制定超标准洪水情况下的防洪对策; 对望虞河和太浦河加强管理, 提高效率, 最大限度发挥排洪能力.

研究工程防洪措施: 从流域社会经济可持续发展高度出发,研究新辟流域性排水通道和建立滞蓄洪区 的可能性. 同时, 针对流域现状水利工程的薄弱环节,进一步沟通、整合流域水系.

\section{4 结语}

按太湖流域防洪标准的涵义,太湖流域近期防洪体系是由治太 11 大骨干工程为主体的防洪工程与非 工程防洪措施所构成, 重点防治大范围的流域性暴雨洪水; 在流域防洪规划条件下, 确保流域防洪体系正常 运行,结合城市防洪工程和区域防洪工程措施,保护流域内地级以上城市免除洪水灾害,将流域总体灾害损 失控制在规定标准之内.

鉴于太湖流域大暴雨时空分布的不确定性,建议在均匀型设计暴雨的基础上,采用各种典型的时空分 布暴雨进行防洪校核, 以保证防洪规划结果的安全可靠. 分析表明, 目前太湖流域整体防洪能力低于 50 年 一遇, 进一步提高太湖流域防洪标准必须更好地衔接流域、区域和城市防洪规划, 加强非工程防洪措施及研 究新辟流域性排水通道可能性.

\section{5 参考文献}

[1] 水利部长江水利委员会水文局. 水利水电工程水文计算规范. 北京: 中国水利水电出版社,2002.

[2] 王俊德. 水文统计. 北京: 水利电力出版社,1993.

[3] 王同生. ’ 99 洪水和对进一步治理太湖的探讨. 水科学进展,2001,12(1):87 - 94 .

[4] 吴泰来. 太湖流域 1999 年特大洪水和防洪规划的思考. 水利规划, 2000,(1):32-36.

[5] 毛 锐. 建国以来太湖流域三次洪水的比较及对今后治理洪涝的意见. 湖泊科学, 2000,12(1):12 -18 .

[6] 徐雪红 太湖流域防洪形势及近期治理防洪标准探讨. 湖泊科学,2000,12(3): 199-204.

[7] 徐林柱,姚文广.太湖流域防洪及减灾对策. 中国水利,2004,(6):47-48.

[8] 林泽新. 太湖流域防洪工程建设及减灾对策. 湖泊科学,2002,14(1):13-18.

[9] 徐向阳,刘 俊. 水旱灾害损失评估系统. 灾害学, 1999,14(1):1-5.

[10] 姜付仁, 程晓陶, 向立云, 吴玉成. 美国 20 世纪洪水损失分析及中美 90 年代比较研究. 水科学进展, $2003,14(3): 384-388$.

[11] 庞进武,徐雪红, 张祥伟. 关于太湖流域治理规划的思考. 中国水利, 2004, (16):18-20.

[12] 陈茂满. 从科学发展观看太湖流域治理. 江苏水利,2005, (1):11-13.

[13] 徐家贵, 贾更华. 太湖流域近期防洪战略. 水利规划设计, 2002, (2) :48 - 51. 